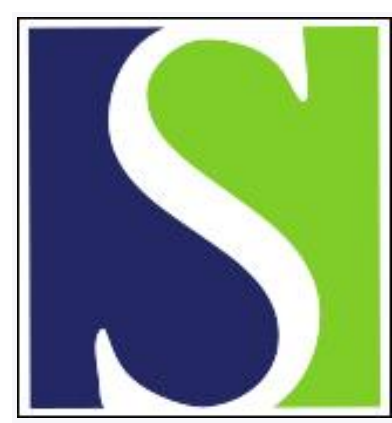

Scand J Work Environ Health 2001;27(4):287-291

https://doi.org/10.5271/sjweh.616

Issue date: Aug 2001

Socioeconomic status, workplace characteristics and plasma fibrinogen level of Japanese male employees

by Ishizaki M, Martikainen P, Nakagawa H, Marmot M; The Japan Work Stress and Health Cohort Study Group

Affiliation: Health Care Centre, Kanazawa Medical University, 1-1 Daigaku, Uchinada, Ishikawa 9200293 , Japan. issa1@kanazawa-med.ac.jp

The following article refers to this text: 2002;28(4):238-248

Key terms: employee; employment grade; Japan; job demand-control; male; overtime; plasma fibrinogen level; socioeconomic status; workplace characteristics

This article in PubMed: www.ncbi.nlm.nih.gov/pubmed/11560343 


\title{
Socioeconomic status, workplace characteristics and plasma fibrinogen level of Japanese male employees
}

\author{
by Masao Ishizaki, PhD, ${ }^{1}$ Pekka Martikainen, PhD, ${ }^{2}$ Hideaki Nakagawa, PhD, ${ }^{3}$ Michael Marmot, PhD, ${ }^{2}$ The \\ Japan Work Stress and Health Cohort Study Group ${ }^{4}$
}

\begin{abstract}
Ishizaki M, Martikainen P, Nakagawa H, Marmot M, The Japan Work Stress and Health Cohort Study Group. Socioeconomic status, workplace characteristics and plasma fibrinogen level of Japanese male employees. Scand J Work Environ Health 2001;27(4):287-291.

Objectives This study examined the relationships between workplace characteristics and plasma fibrinogen level and assessed the possibility of socioeconomic differences in plasma fibrinogen level being accounted for by workplace characteristics.

Methods Cross-sectional questionnaire data from 4343 Japanese male employees were examined with Karasek's demand-control model, as was sedentary job and overtime work.

Results Less overtime work, a less sedentary job, and to a less extent, lower job control and low worksite support were related to increased plasma fibrinogen levels. Adjusting for employment grade strongly attenuated or eliminated these relationships. The association of job demands or job strain with plasma fibrinogen level was weak. High plasma fibrinogen in lower socioeconomic groups remained largely unchanged after adjustment for workplace characteristics.

Conclusions Workplace characteristics are not significantly related to the plasma fibrinogen levels of male Japanese employees after adjustment for socioeconomic status, and they do not explain socioeconomic differences in plasma fibrinogen levels among these employees.
\end{abstract}

Key terms employment grade, job demand-control, overtime.

Socioeconomic status inequalities in coronary heart disease, namely, a greater risk of developing coronary heart disease among those of lower socioeconomic status than those of higher socioeconomic status, have been observed in western European countries and the United States (1-3). It has been postulated that one of the biological mechanisms underlying this relationship is associated with differences in plasma fibrinogen, which is a risk factor for coronary heart disease $(4,5)$. We have previously found that there is an inverse association between employment grade and plasma fibrinogen level for Japanese male employees $(6,7)$.
Workplace characteristics, in particular job strain defined as high job demand and low job control, job strain with low social support at work, and high effort in combination with low rewards at work, have also been proposed to be associated with coronary heart disease (8-11). However, some studies suggest that only job control is related to coronary heart disease $(12,13)$. In Japan long workhours have also been related to myocardial infarction (14). It is possible, therefore, that workplace characteristics may contribute to socioeconomic inequalities in plasma fibrinogen and coronary heart disease.

2 International Centre for Health and Society, Department of Epidemiology and Public Health, University College London Medical School, London, United Kingdom.

3 Department of Public Health, Kanazawa Medical University, Ishikawa, Japan.

4 The following members of The Japan Work Stress and Health Cohort Study Group are also co-authors of the manuscript: Norito Kawakami, PhD (Okayama Medical School); Takashi Haratani, PhD, Shunichi Araki, PhD (National Institute of Industrial Health, Japan Ministry of Labor); Fumio Kobayashi, PhD (Aichi Medical University).

Reprint requests to: Masao Ishizaki, Health Care Centre, Kanazawa Medical University, 1-1 Daigaku, Uchinada, Ishikawa 920 0293, Japan. [E-mail: issa1@kanazawa-med.ac.jp] 
In this study, we analyzed cross-sectional data to examine the relationship between workplace characteristics and plasma fibrinogen level and also to assess whether adjusting for workplace characteristics attenuates the observed relationship between socioeconomic status and plasma fibrinogen level.

\section{Subjects and methods}

Our subjects were full-time white- and blue-collar male employees who were between the ages of 20 and 58 years, were registered on the payroll of a Japanese metal products factory in a Toyama prefecture as of 1 May 1996, and underwent a medical check-up between April 1996 and March 1997. A questionnaire covering the workplace characteristics was administered within a month before or after a person underwent the medical checkup, and a questionnaire concerning life-style was filled out at the time of the medical check-up.

Our analyses excluded junior employees who had worked for less than a year, short-term employees from recruitment agencies, a few directors, and 43 employees who underwent a medical check-up at another medical facility, 48 employees who were receiving treatment for coronary heart disease, renal failure or arthritis and 4 subjects whose plasma fibrinogen data were not available. There were 4343 participants, and the participation rate was $92.2 \%$.

The employment grade, our measure of socioeconomic status, was based on information on individual salary obtained from the factory records. Originally there were nine salary grades. However, because of the relatively small number of participants in the four highest grades, we combined them into one. Consequently, six hierarchical employment grades from low to high status were used in this study.

Individual workplace characteristics - job demands, job control and worksite support - were determined by the Japanese version of Karasek's job demandcontrol model. Available evidence suggests that this is a valid and reliable measure of job stressors in the Japanese population (15). Sedentary job and overtime work were assessed by a self-administered questionnaire. Job demands, job control, and worksite support were classified by quartile. Sedentary job was categorized into four groups according to the average sedentary hours per workday in the past year (almost none, $<1$ hour, $1-4$ hours, and $>4$ hours). Overtime work was categorized into four groups according to the sum of the overtime workhours during the past month $(\leq 5$ hours, $>5-15$ hours, $>15-25$ hours, and $>25$ hours). We also distinguished between white- and blue-collar workers on the basis of the results of the self-administered question- naire because of previous evidence indicating that the influence of job control on coronary heart disease is greater for white-collar workers than for blue-collar workers (12).

Information about life-style included smoking habits, alcohol consumption, and physical activity during leisure time. Smoking habits were classified according to whether the worker was a nonsmoker, an ex-smoker, smoked $<21$ cigarettes a day, or smoked $\geq 21$ cigarettes a day. Alcohol consumption was measured in terms of grams of ethanol consumed per week and was based on the quantity of specified drinks consumed weekly. Leisure-time physical activity was classified as almost no exercise, light exercise per week, brisk and sweating exercise once or twice per week, and brisk and sweating exercise more than three times per week.

We adjusted for age in all the statistical analyses. The data were analyzed by means of Spearman's partial rank correlations and linear regression analyses of the contribution of explanatory variables to the plasma fibrinogen level. The plasma fibrinogen level was logarithmically transformed for the analyses. We considered age, body mass index (BMI) $\left(\mathrm{kg} / \mathrm{m}^{2}\right)$, height, waist-hip ratio, smoking and alcohol consumption, leisure-time exercise, systolic blood pressure, white blood cell counts and hemoglobin A1c as confounding factors (16). The results adjusted for waist-hip ratio are not shown because of missing values. However, in a partial data set with full information, adjustment for waist-hip ratio did not affect the association between work characteristics and plasma fibrinogen level. Sedentary job, overtime work, smoking, and leisure-time physical activity were categorized into four levels in all the analyses. For the statistical analyses the PC-SAS program package (SAS Institute Inc., Cary, North Carolina, United States) was used.

\section{Results}

Two hundred and thirty-two subjects did not reply at all to the questionnaire on the five workplace characteristics. In addition, 171 subjects provided only partial information. There was no statistically significant difference between the mean level of plasma fibrinogen for the 3919 subjects with full information on all the variables and that of the 424 subjects with partial information $(\mathrm{P}=0.76)$.

The results of the Spearman's partial rank correlations between the employment grades and the workplace characteristics indicated that employment grade was strongly correlated with job control (0.42), sedentary job $(0.55)$, and overtime work (0.40) (ie, people who were in the high employment grades had higher control, 
Table 1. Regression coefficients ${ }^{a}$ and $95 \%$ confidence intervals $(95 \% \mathrm{Cl})$ of the workplace characteristics ${ }^{b}$ in relation to plasma fibrinogen level. ( $\mathrm{I}=$ adjustment for age, $\mathrm{I}$ = adjustment for I and employment grade categorized into six hierarchical groups (the lowest=1, the highest=6), III = adjustment for II, body mass index (BMI), height, smoking and alcohol consumption, leisure-time exercise, systolic blood pressure, white blood cell counts and hemoglobin A1c)

\begin{tabular}{|c|c|c|c|c|c|c|c|c|c|}
\hline & \multicolumn{3}{|c|}{1} & \multicolumn{3}{|c|}{ II } & \multicolumn{3}{|c|}{ III } \\
\hline & $\begin{array}{l}\text { Number } \\
\text { of subjects }\end{array}$ & $\begin{array}{c}\text { Coefficient } \\
(\%)\end{array}$ & $95 \% \mathrm{Cl}$ & $\begin{array}{c}\text { Number } \\
\text { of subjects }\end{array}$ & $\begin{array}{c}\text { Coefficient } \\
(\%)\end{array}$ & $95 \% \mathrm{Cl}$ & $\begin{array}{l}\text { Number } \\
\text { of subjects }\end{array}$ & $\begin{array}{c}\text { Coefficient } \\
(\%)\end{array}$ & $95 \% \mathrm{Cl}$ \\
\hline $\begin{array}{l}\text { Job control } \\
\text { Job demands } \\
\text { Worksite support } \\
\text { Sedentary job } \\
\text { Overtime work }\end{array}$ & $\begin{array}{l}4076 \\
4082 \\
4065 \\
4081 \\
4057\end{array}$ & $\begin{array}{l}-0.43 \\
-0.19 \\
-0.41 \\
-0.63 \\
-0.79\end{array}$ & $\begin{array}{l}-0.92 \sim 0.06 \\
-0.68 \sim 0.30 \\
-0.99 \sim 0.18 \\
-1.09 \sim-0.16 \\
-1.27 \sim-0.30\end{array}$ & $\begin{array}{l}4076 \\
4082 \\
4065 \\
4081 \\
4057\end{array}$ & $\begin{array}{r}0.10 \\
-0.11 \\
-0.33 \\
0.02 \\
-0.30\end{array}$ & $\begin{array}{l}-0.43 \sim 0.63 \\
-0.60 \sim 0.38 \\
-0.91 \sim 0.26 \\
-0.53 \sim 0.57 \\
-0.83 \sim 0.23\end{array}$ & $\begin{array}{l}4055 \\
4061 \\
4045 \\
4060 \\
4036\end{array}$ & $\begin{array}{r}0.10 \\
-0.06 \\
-0.23 \\
0.26 \\
-0.10\end{array}$ & $\begin{array}{l}-0.41 \sim 0.61 \\
-0.53 \sim 0.41 \\
-0.78 \sim 0.32 \\
-0.27 \sim 0.79 \\
-0.61 \sim 0.41\end{array}$ \\
\hline
\end{tabular}

a Percentage of change in the plasma fibrinogen level per unit of change in the explanatory variable.

${ }^{b}$ Job control, job demands and worksite support are categorized into quartiles; sedentary job and overtime work are categorized into four groups. (See the Methods secton.)

a more sedentary job, and increased overtime work than people who were in low employment grades). Job demands (0.07) and worksite support (0.06) were weakly correlated with employment grade.

Column I in table 1 shows the age-adjusted relationships between the workplace characteristics and plasma fibrinogen level from the linear regression models. The plasma fibrinogen levels were significantly increased for less sedentary jobs and less overtime work. Low job control $(\mathrm{P}=0.07)$ and less worksite support $(\mathrm{P}=0.17)$ also tended to be related to an increase in plasma fibrinogen. However, there were no significant associations between the workplace characteristics and plasma fibrinogen level after adjustment for employment grade. Adjusting for educational qualification instead of employment grade also abolished the effects of workplace characteristics on plasma fibrinogen levels (results not shown).

After adjustment for the confounding factors, more overtime work for white-collar employees tended to be associated with an increase in the plasma fibrinogen level $(\beta=0.68 \%, P=0.11)$. In contrast, more overtime work for blue-collar employees tended to be related to a decrease in the plasma fibrinogen level $(\beta=-0.55 \%$, $\mathrm{P}=0.13$ ). However, the difference between the whitecollar and blue-collar workers was not significant at the 5\% level. The relationships between the other workplace characteristics and plasma fibrinogen level were similar for both the white-collar and blue-collar employees (results not shown). There were no significant interactions between job control, job demands, and worksite support.

The age-adjusted plasma fibrinogen level was significantly increased in the lower employment grades; one unit increase in employment grade was associated with a $1.26 \%$ [95\% confidence interval $(95 \% \mathrm{CI})-1.72$ $\sim-0.80$ ] decrease in the plasma fibrinogen level (table 2). The corresponding figures for the white-collar and bluecollar employees were $-2.73 \%$ (95\% CI $-3.78 \sim-1.68$ )
Table 2. Regression coefficients and $95 \%$ confidence intervals $(95 \% \mathrm{Cl})$ of the employment grade in relation to the plasma fibrinogen level adjusted for the workplace characteristics.

\begin{tabular}{llc}
\hline & \multicolumn{2}{c}{ Employment grade ${ }^{\mathrm{a}}$} \\
\cline { 2 - 3 } & $\begin{array}{c}\text { Coefficient } \\
(\%)\end{array}$ & $95 \% \mathrm{Cl}$ \\
\cline { 2 - 3 } & -1.26 & $-1.72 \sim-0.80$ \\
Age & -1.34 & $-1.86 \sim-0.82$ \\
Age and job control & -1.26 & $-1.72 \sim-0.80$ \\
Age and job demands & -1.25 & $-1.71 \sim-0.79$ \\
Age and worksite support & -1.27 & $-1.83 \sim-0.71$ \\
Age and sedentary job & -1.15 & $-1.64 \sim-0.65$ \\
Age and overtime work & -1.26 & $-1.85 \sim-0.66$ \\
Age and all workplace characteristics & -1.08 & $-1.65 \sim-0.50$ \\
All variables ${ }^{\mathrm{b}}$ (N=3919) &
\end{tabular}

a Employment grade categorized into six hierarchical groups (lowest $=1$, highest =6).

${ }^{b}$ Adjusted for age, workplace characteristics, and the same biological and behavioral factors as in III of table 1.

and $-0.25 \%$ (95\% CI $-0.96 \sim 0.45$ ), respectively. After adjustment for workplace characteristics and behavioral and biological explanatory factors, these associations were only slightly attenuated.

\section{Discussion}

In our cross-sectional data on Japanese male employees, less overtime work, a less sedentary job, lower job control, and low worksite support were related to increased plasma fibrinogen levels. Adjustment for employment grade strongly attenuated or eliminated these relationships. There were no clear relationships between job demands or job strain and the plasma fibrinogen level.

The nature and public health relevance of the contribution of work characteristics to plasma fibrinogen levels has not been conclusively established, as both positive and negative results have been obtained (17-20). 
Of the positive studies, a Danish study of middle-aged men and women showed that low job control rather than high job demands and subjective job strain were related to an increase in plasma fibrinogen levels (21). Similarly, a study of a random sample of Swedish citizens living in Stockholm county reported that the clearest evidence for psychosocial effects on plasma fibrinogen seems to be related to job control and the associations are clearer for objective variables than for self-report variables. These associations were relatively weak but were somewhat more important for female employees (22).

Low job control was also associated with a high plasma fibrinogen level in Whitehall male civil servants. However, this relationship was considerably attenuated when socioeconomic status was taken into consideration (23). The results of our study were similar to those of the Whitehall II study in this respect. Future studies on work characteristics and fibrinogen need to acknowledge the possibly strong confounding or moderating effects of socioeconomic status, particularly in studies using externally rated work characteristics. The accumulated evidence of both positive and negative studies suggests that the effect of work characteristics on plasma fibrinogen varies for men and women, depending on the particular work characteristic measures in question and the use of self-reports or objective measurement methods.

Although conclusive evidence is not yet available, we have some reason to believe that a social gradient in cardiovascular disease exists in Japan (24). Consistent with this possibility, our study showed a significant association between employment grade and plasma fibrinogen level. This association was only slightly attenuated after adjustment for workplace characteristics and behavioral and biological explanatory factors.

Our results agree with those of several other studies $(19,23,25)$ that showed that socioeconomic status is related to plasma fibrinogen levels. However, our study further showed that this relationship is not mediated by socioeconomic differences in standard behavioral and biological determinants of fibrinogen or differences in psychosocial stress as assessed by adverse work characteristics. The determinants of the effects of socioeconomic status on plasma fibrinogen clearly need more study.

In conclusion, after adjustment for socioeconomic status, workplace characteristics were not significantly related to plasma fibrinogen level among Japanese male employees. Furthermore, the workplace characteristics we investigated did not explain the socioeconomic differences in the plasma fibrinogen levels of our cohort. Thus, in our data, work characteristics did not seem to be strong mediators of the effects of socioeconomic status on plasma fibrinogen in Japanese male employees.

\section{References}

1. Valkonen T. Adult mortality and level of education: a comparison of six countries. In: Fox J, editor. Health inequalities in European countries. Aldershot: Gower Publishing Ltd, 1989:142-6.

2. Marmot MG, Smith GD, Stansfeld S, Patel C, North F, Head J, et al. Health inequalities among British civil servants: the Whitehall II study. Lancet 1991;337:1387-93.

3. Davey-Smith G, Neaton JD, Wentworth D, Stamler R, Stamler J. Mortality differences between black and white men in the USA: contribution of income and other risk factors among men screened for the MRFIT. Lancet 1998;351:934—9.

4. Rosengren A, Wilhelmsen L, Welin L, Tsipogianni A, TegerNilsson AC, Wedel H. Social influences and cardiovascular risk factors as determinants of plasma fibrinogen concentration in a general population sample of middle aged men. BMJ 1990;300:634-8.

5. Brunner EJ, Marmot MG, White IR, O'Brien JR, Etherington $\mathrm{MD}$, Slavin BM, et al. Gender and employment grade differences in blood cholesterol, apolipoproteins and haemostatic factors in the Whitehall II study. Atherosclerosis 1993;102:195-207.

6. Ishizaki M, Martikainen P, Nakagawa H, Marmot MG. The relationship between employment grade and plasma fibrinogen level among Japanese male employees. Atherosclerosis 2000;151:415-21.

7. Martikainen P, Ishizaki M, Marmot MG, Nakagawa H. Socioeconomic differences in behavioural and biological risk factors: a comparison of a Japanese and an English cohort of employed men. Int J Epidemiol. In press.

8. Karasek RA, Baker D, Marxer F, Ahlbom A, Theorell T. Job decision latitude, job demands, and cardiovascular disease: a prospective study of Swedish men. Am J Public Health 1981;71:694-705.

9. Johnson JV, Hall EM. Job strain, work place social support, and cardiovascular disease: a cross-sectional study of a random sample of the Swedish working population. Am J Public Health 1988;78:1336-42.

10. Siegrist J, Peter R, Junge A, Cremer P, Seidel D. Low status control, high effort at work and ischemic heart disease: prospective evidence from blue-collar men. Soc Sci Med 1990;31:1127-34.

11. Theorell T, Tsutsumi A, Hallquist J, Reuterwall C, Hogstedt C, Fredlund P. Decision latitude, job strain, and myocardial infarction: a study of working men in Stockholm. Am J Public Health 1998;88:382-8.

12. Alterman T, Shekelle RB, Vernon SW, Burau KD. Decision latitude, psychologic demand, job strain, and coronary heart disease in the Western Electric Study. Am J Epidemiol 1994;139:620-7.

13. Bosma H, Marmot MG, Hemingway H, Nicholson AC, Brunner E, Stansfeld SA. Low job control and risk of coronary heart disease in Whitehall II (prospective cohort) study. BMJ 1997;314:558-65.

14. Sokejima S, Kagamimori S. Working hours as a risk factor for acute myocardial infarction in Japan: case-control study. BMJ 1998;317:775-80.

15. Kawakami N, Kobayashi F, Araki S, Haratani T, Furui H. Assessment of job stress dimensions based on the job demands-control model of employees of telecommunication and electric power companies in Japan: reliability and validity of the Japanese version of job content questionnaire. Int $\mathrm{J}$ 
Behav Med 1995;2:358-75.

16. Folsom AR. Epidemiology of fibrinogen. Eur Heart J 1995;16 (suppl A):21-3.

17. Markowe HL, Marmot MG, Shipley MJ, Bulpitt CJ, Meade TW, Stirling Y, et al. Fibrinogen: a possible link between social class and coronary heart disease. BMJ 1985; 291:1312-4.

18. Folsom AR, Qamhieh HT, Flack JM, Hilner JE, Liu K, Howard BV, et al. Plasma fibrinogen: levels and correlates in young adults. The coronary artery risk development in young adults (CARDIA) study. Am J Epidemiol 1993;138:102336.

19. Moller L, Kristensen TS. Plasma fibrinogen and ischemic heart disease risk factors. Arterioscler Thromb 1991; 11:344-50.

20. Mattiasson I, Lindgärde F. The effect of psychosocial stress and risk factors for ischaemic heart disease on the plasma fibrinogen concentration. J Intern Med 1993;234:45-51.

21. Netterstrom B, Kristensen TS, Damsgaard MT, Olsen O, Sjol A. Job strain and cardiovascular risk factors: a cross sectional study of employed Danish men and women. Br J Ind Med 1991;48:684-9.

22. Tsutsumi A, Theorell T, Hallqvist J, Reuterwall C, Faire U. Association between job characteristics and plasma fibrinogen in a normal working population: a cross sectional analysis in referents of the SHEEP study. J Epidemiol Community Health 1999;53:348-54.

23. Brunner EJ, Smith GD, Marmot M, Canner R, Beksinska M, O'Brien JR. Childhood social circumstances and psychosocial and behavioural factors as determinants of plasma fibrinogen. Lancet 1996;347:1008-13.

24. Kagamimori S, Matsubara I, Sokejima S, Sekine M, Matsukura T, Nakagawa H, et al. The comparative study on occupational mortality, 1980 between Japan and Great Britain. Ind Health 1998;36:252-7.

25. Colhoun H, Clarke PP. Health survey for England 1994. London: HMSO, 1996.

Received for publication: 2 February 2001 